\title{
Comunalidades rurales en reedición: encierros comunitarios y ganaderos en Santiago del Estero (Argentina)
}

\author{
Rural communalities in reedition: Communal and livestock enclosures in Santiago \\ del Estero (Argentina)
}

\author{
Ana Eliza Villalba ${ }^{1}$ (D), Andrea Geanina Gómez Herrera ${ }^{1}$ (D), Raul Gustavo Paz ${ }^{1}$ (D) \\ ${ }^{1}$ Instituto de Estudios para el Desarrollo Social, Facultad de Humanidades, Ciencias Sociales y de la Salud, Universidad \\ Nacional de Santiago del Estero (UNSE), Santiago del Estero, Argentina. E-mails: ani.villalba89@gmail.com; \\ andreagh90@gmail.com; pazraul5@hotmail.com
}

\begin{abstract}
Cómo citar: Villalba, A. E., Gómez Herrera, A. G., \& Paz, R. G.. (2020). Comunalidades rurales en reedición: encierros comunitarios y ganaderos en Santiago del Estero (Argentina). Revista de Economia e Sociologia Rural, 58(3), e219343. https://doi.org/10.1590/1806-9479.2020.219343
\end{abstract}

Resumen: En Santiago del Estero (Argentina), la persistencia de explotaciones sin límites definidos encuentra relación con el desarrollo de comunalidades en el espacio rural provincial. El objetivo del trabajo es analizar la articulación entre las condiciones estructurales y las prácticas que operan en la constitución y reedición de las relaciones comunales en el paraje rural El Hoyo ubicado en Santiago del Estero, Argentina. A partir de registros censales y mediantes un análisis cualitativo de entrevistas en profundidad se da cuenta de la emergencia de los encierros ganaderos y comunitarios, en tanto formato productivo anclado en una matriz comunal y que responde al despliegue de prácticas en las que subyace lógicas de vinculación comunitarias. Asimismo, se tensiona una visión que asocia la presencia de explotaciones sin límites definidos y las formas de organización comunal con pobreza rural y atraso, reflexionando sobre sus potencialidades en la generación de iniciativas alternativas de desarrollo.

Palabras claves: estructura agraria, explotaciones sin límites definidos, matriz comunal, encierros ganaderos, lógicas comunitarias.

Abstract: In Santiago del Estero (Argentina), the persistence of exploitations without defined limits is related to the development of communalities in the provincial rural area. The paper aims to analyze the relationship between the structural conditions and practices operating in the constitution and the reedition of communal relations in El Hoyo rural community. From census records and through a qualitative analysis of in-depth interviews, we intended to account for the emergence of communal livestock enclosures, as a productive format anchored in a communal matrix that responds to the deployment of practices that underlies logics of community ties. Likewise, it tenses a vision that associates the presence of exploitation without defined limits and forms of communal organization with rural poverty and backwardness, reflecting on their potential in the generation of alternative development initiatives.

Keywords: agrarian structure, exploitation without defined limits, communal matrix, communal enclosures, community logics.

\section{Introducción}

Los estudios clásicos, principalmente liberales y marxistas, defendían la inexorable desaparición de las formas comunales y del campesinado como sujeto social agrario constitutivo de dichas organizaciones sociales, para dar paso al desarrollo pleno de las formas capitalistas. Pues la propiedad colectiva de la tierra, las relaciones de parentesco y las tradiciones, el escaso desarrollo de las fuerzas productivas eran obstáculos para los 
procesos de mercantilización y acumulación capitalista (Marx 1851-1852 citado en García Linera, 2009).

En la actualidad nuevas perspectivas como el poscapitalismo manifiestan que las distintas formas de comunalismo constituyen instituciones vivas, resilientes y capaces de generar alternativas de desarrollo (Giménez Romero, 1991). Por otro lado, la comunalidad como una visión colectiva aporta al debate desde el estudio de las comunidades campesinas e indígenas mesoamericanas (Martínez Luna, 2015). La comunalidad se presenta como la lógica con la que funciona la estructura social y la forma en que se define y articula la vida social y su convivir cotidiano (Flores et al., 2014).

Desde la nueva ruralidad comunitaria, se rescatan los esfuerzos en proponer un modelo de análisis de las estrategias contestatarias que despliegan las comunidades rurales frente a la racionalidad económica dominante, el cual representa las relaciones que se dan entre las categorías de comunalidad, autonomía y procesos de apropiación de la naturaleza. Como resultado, los elementos que se manifiestan son la democracia participativa o consensual, la organización del trabajo comunitario, la posesión territorial comunitaria, la construcción de identidad cultural y la cosmovisión, como procesos que conforman la comunalidad (Fuente Carrasco, 2012). La autonomía es integrada por procesos como la formación político-cultural, el desarrollo de las fuerzas productivas comunitarias, la diversificación del mercado, la formación de redes de apoyo y la soberanía alimentaria (Fuente Carrasco, 2009; Barkin \& Lemus, 2015).

Otras experiencias actuales que dan cuenta de esta dinámica son las comunidades tradicionales en Brasil, emplazadas en áreas forestales y que desarrollan un modo particular de vida en constante interdependencia con la naturaleza, procurando garantizar la utilización de los recursos naturales para las siguientes generaciones. Estas comunidades se diferencian de otras formas de organización social al ocupar el territorio para la reproducción social, cultural y económica, auto-reconociéndose como pertenecientes a estos pueblos tradicionales y con el objetivo de que las formas de transformación de los bienes comunes resulten en sistemas alimentarios locales integrados sin caer en el extractivismo (Grzebieluka, 2012; Guerra Brayner, 2019). Mientras que para Argentina las explotaciones sin límites definidos constituyen una categoría censal utilizada para cuantificar la estructura agraria, en Brasil es una categoría socio-territorial establecida por el Estado en la Constitución Federal de 1988 en la que principios multiculturalistas se afirman (Raimbert, 2013). Sin embargo, ambas categorías tienen problemáticas comunes, en especial cuando se observa la expansión de la frontera agropecuaria llevada adelante por el agronegocio y la tensión que se genera por la presión de la tierra en esas comunidades rurales .

En consonancia con estas experiencias, existe un complejo de condiciones y procesos contemporáneos frente a los que cabe preguntarse cómo se producen comunalidades en el espacio rural. Una característica singular de esta porción del territorio argentino es la existencia de amplias superficies de tierra denominadas explotaciones sin límites definidos, las cuales fueron históricamente asociadas con visiones de pobreza extrema y con un actor social agrario ${ }^{1}$ que presenta situaciones problemáticas de tenencia de la tierra que se relacionan con las ocupaciones de tierras privadas, fiscales, campos comuneros, comunidades indígenas, áreas nacionales protegidas, entre otras (Slutzky, 2008). Para el capitalismo agrario, la ausencia de límites precisos y de propiedad sobre la tierra no constituye un buen escenario para el desarrollo de las fuerzas productivas. El régimen comunal constituye un obstáculo a las fuerzas productivas (Marx, 1986) y anima a pensar en su completa transformación y posterior desaparición.

Estas explotaciones sin límites definidos, constituyen una categoría censal la cual se incorpora en el Censo Nacional Agropecuario de 1988 (CNA 88') con el objeto de captar a un tipo de explotación agropecuaria (EAP) muy particular y frecuentes en las regiones más pobres de Argentina. La tierra que compone a estas EAPs no está bien delimitada y para

\footnotetext{
${ }^{1}$ Este sector ha recibido varios nombres y clasificaciones según distintos autores y territorios en los que habitan: campesino ocupante (Paz, 2006, 2011, 2013), campesino con ánimo de dueño (De Dios \& Williams, 1998; De Dios, 2012).
} 
evitar duplicaciones, su superficie total no es registrada por el censo (INDEC, 1988 citado en Paz, 2011). Tanto para el CNA 88' como para los sucesivos censos nacionales agropecuarios (CNA 2002 y 2008) se utilizan dos tipos de cuestionario: uno destinado a las explotaciones con límites definidos y el otro, un cuestionario especial, para las explotaciones sin límites precisos donde no se registra la cantidad de hectáreas que componen la EAP.

Esta original perspectiva metodológica permite según el CNA 88', identificar una estructura agraria argentina compuesta por 421.221 EAPs, de las cuales cerca del $11 \%$ conforman la categoría de EAPs sin límites definidos. Sin embargo, al momento de analizar por región se observa que dicha distribución no es homogénea. El 70\% del total de EAPs sin límites se encuentran concentradas en la región del Noroeste Argentino (NOA) y del Noreste Argentino (NEA), en contraste con la región más rica del país (Pampa Húmeda) que sólo posee menos del $2 \%$.

Sin embargo, las EAPs sin límites definidos, a lo largo de la historia, han mostrado dos cuestiones que resultan interesantes de rescatar para ser pensadas desde una perspectiva de alternativas al desarrollo capitalista. La primera está dada por su capacidad de sobrevivencia y reproducción por parte de los actores sociales agrarios que habitan en este tipo de explotaciones agropecuarias. Al comparar los datos que arrojan los censos (CNA 88' y CNA 02') se observa en la región del Noroeste Argentino (NOA), un crecimiento de las explotaciones sin límites, tanto en términos absolutos (1.837 nuevas explotaciones) como relativos respecto al total de las explotaciones agropecuarias (2,13\%). En consecuencia este sector más allá de desaparecer o ir debilitándose va construyendo una conducta defensiva donde el monte conjuntamente con lo pecuario constituyen su principal basamento.

La segunda cuestión, asociada a la anterior y que de alguna manera permite comprender la sobrevivencia de este sector, es su carácter de mancomunalidad que se ve reflejada tanto en las estrategias de uso común de bienes (como tierra, monte y el agua) como en la utilización de la mano de obra por parte de los pobladores rurales. Existe una lógica comunal que se ha venido expresando a lo largo del tiempo y que se materializa en la cotidianeidad pasada y presente de las prácticas llevadas adelante por parte de los pobladores rurales ubicados en las explotaciones sin límites.

Un territorio cuyas características centrales son condiciones climáticas adversas, un ambiente hostil pero a la vez generoso en recursos como lo es el monte (miel, cera, madera, animales silvestres, frutos del monte, plantas tintóreas y medicinales, etc.), grandes extensiones de tierra y condiciones agroecológicas frágiles para la producción agropecuaria, exige de un entramado social con una compleja red demográfica, de división de roles y generacional orientada a cubrir la propia reproducción. En otras palabras, la base de funcionamiento de estos sistemas sociales y de producción a monte abierto, tanto en el pasado como en el presente, lo constituye la constante e intensa utilización de energía humana tanto en los procesos de recolección como productivos, que muchas veces superan al esfuerzo individual y su propio entorno familiar para ser sorteado desde una perspectiva comunal (Palomeque, 1992; Farberman, 2006). Estos dos aspectos que testimonian las explotaciones sin límites definidos, hace pensar en la presencia de una matriz comunal que se remonta a la formas de posesión alternativas a la propiedad privada individual en el período colonial, pero que persisten hasta la actualidad sostenidas por un entramado de relaciones sociales.

El paraje El Hoyo, ubicado en la provincia de Santiago del Estero (Argentina), en el cual existen explotaciones sin límites definidos, presenta un sistema social y de producción basado en la posesión comunitaria de la tierra, formas colectivas de organización y otros elementos de una cultura del mancomún. Sus pobladores han mostrado la capacidad de rediseñar su matriz comunal al momento de defender la tierra ante los intentos de desalojos. La lucha por la defensa de la tierra emprendida por esta comunidad tuvo una base productiva y comunal, dando lugar a la creación de encierros ganaderos y comunitarios durante la implementación de programas estatales de desarrollo rural.

El problema de investigación del presente artículo busca responder al interrogante ¿cómo se producen relaciones comunales en el marco de la defensa en y por la tierra de los pobladores rurales del paraje El Hoyo en Santiago del Estero? En este sentido, el objetivo 
principal del trabajo es analizar la articulación entre las condiciones estructurales y las prácticas de estos pobladores para comprender como se despliegan comunalidades en el espacio rural, buscando tensionar una visión que asocia la presencia de explotaciones sin límites definidos y las formas de organización comunal con pobreza rural y atraso, reflexionando sobre sus potencialidades en la generación de iniciativas alternativas de desarrollo.

En virtud de lo expuesto, en primer término se aborda la conformación de la estructura agraria de Santiago del Estero, a partir de fuentes censales y referencias históricas, a fin de dilucidar los procesos que fueron moldeando matrices comunales en el espacio rural de la provincia. Posteriormente, se presenta el caso de estudio, desde la articulación entre las condiciones agroecológicas, los bienes comunes que detentan los pobladores y las redes de relaciones que entablan en torno al manejo y gestión de estos bienes en El Hoyo. Luego se abordan las prácticas de pobladores y agentes estatales que derivan en un diseño productivo pecuario congruente con dicha matriz, denominado encierro ganadero. Por último, se busca poner en tensión la visión que asocia la presencia de explotaciones sin límites definidos y las formas de organización comunal con pobreza rural y atraso, reflexionando sobre sus potencialidades en la generación de iniciativas alternativas al desarrollo.

\section{Principales fuentes y Metodología empleada}

El trabajo plantea un abordaje metodológico cualitativo, en el que a partir de fuentes primarias y secundarias pretende dar cuenta de la emergencia de los encierros ganaderos y comunitarios, en tanto formato productivo anclado en una matriz comunal el cual responde al despliegue de prácticas en las que subyacen lógicas de vinculación comunitarias.

Se utilizaron los datos censales del CNA de 1988 y aquellos recabados en el año 2002. Se tomó esta decisión metodológica, ya que la confiabilidad de la información provista por el último CNA realizado en Argentina durante el año 2008 es cuestionada debido a las dificultades técnicas y políticas acaecidas durante el relevamiento. En el año 2008, el CNA se efectuó en el marco del conflicto agrario entre las distintas organizaciones de productores y el gobierno nacional, a raíz de la sanción del proyecto de Ley 125, cuya principal fuente de conflicto fue el impuesto a las retenciones a cereales y oleaginosas de exportación. Por lo tanto, muchos de los productores se negaron a responder, o no atendieron al personal de campo asignado para el relevamiento censal.

Mediante la estrategia de estudios de casos se buscó avanzar hacia una comprensión profunda y holística del emprendimiento ganadero de El Hoyo, a partir de la experiencia de los actores sociales involucrados. En la selección del caso se consideraron los siguientes criterios: 1) fue una de las experiencias "pioneras", ya que luego de la puesta en marcha de este emprendimiento comunal, se multiplicaron los casos y en la actualidad se registran diecinueve encierros comunitarios orientados a la producción bovina en los departamentos provinciales estudiados (Figueroa y Moreno); 2) su origen está vinculado al enfrentamiento entre los pobladores ocupantes con ánimos de dueño y empresarios que pretendían desalojarlos; 3) gran parte de los cambios en los modos de gestionar el sistema de recursos de uso común y la ejecución de proyectos productivos ganaderos responden a propuestas técnicas realizadas por extensionistas estatales que operaban bajo la órbita del ex Programa Social Agropecuario, el cual devino en Secretaría de Agricultura Familiar de la Nación Argentina.

El trabajo de campo fue desarrollado en un período comprendido por los años 2014-2016 e involucró el registro de observaciones y entrevistas en profundidad, individuales y grupales. Se entrevistaron a los pobladores con ánimo de dueño que residían al momento de la investigación en el paraje El Hoyo (Departamento Moreno). Además, se realizó entrevistas a los extensionistas de la Secretaría de Agricultura Familiar de la Nación que tienen entre ocho a veinte años de antigüedad en el ejercicio de este trabajo e intervienen en los parajes (o lo hicieron en algún momento), principalmente durante los conflictos por la tierra y la puesta en marcha de los emprendimientos productivos bovinos que analizamos en este trabajo. 


\section{Resultados y Discusión}

\subsection{Estructura agraria en Santiago del Estero: una mirada desde los censos y múltiples escalas temporales}

Existe cierto consenso en torno a los elementos constitutivos de la estructura agraria (Stavenhagen, 1969; Gutelman, 1978). Primero, los elementos fundiarios, que involucra los vínculos que el hombre establece con la tierra como bien natural, lo que implica examinar las características que adquieren las relaciones de apropiación social de la tierra y las formas jurídicas de tenencia, que puede ser directa o indirecta. Segundo, los elementos técnico-económicos que actúan en el proceso productivo, como la procedencia de los recursos, los circuitos de comercialización, el grado de capitalización y los tipos de uso de la tierra. Tercero, los elementos sociales de la estructura agraria refieren a los diversos sujetos actuantes en el agro y el entramado de relaciones existentes entre ellos que están anclados en sistemas de normas y valores, instituidos o instituyentes (Bustamante, 2010). En función de las distintas combinaciones de estos elementos, se puede reconocer tres tipos de estructura agraria: unimodal, bimodal y multimodal.

Santiago del Estero, una de las provincias en la región Noroeste Argentino, presenta una estructura agraria bimodal, es decir existe una marcada concentración y polarización de la propiedad, pero además se registran altos porcentajes de formas de tenencia precaria de la tierra. Ambos aspectos junto a otros procesos vinculados con el avance del capitalismo en el agro tornan inteligible la intensa conflictividad agraria ligada a múltiples factores como la inseguridad jurídica sobre los derechos de propiedad, un mercado de tierras ineficiente, la poca inversión y escasa vinculación con la agroindustria, el uso ineficiente del suelo y el bajo nivel de tributación (Paz, 2006, 2013). A partir de los datos del Censo Nacional Agropecuario (CNA) del año 2002, se advierte que las EAPs con un tamaño mayor a mil hectáreas representan el 9,79\% del total provincial y concentran el $75,89 \%$ de tierra. Mientras que las EAPs con un tamaño menor a mil hectáreas representan el 90,21\% y tienen el $24,11 \%$ de la tierra.

Además la provincia exhibe los porcentajes más altos de unidades campesinas dentro de su estructura agraria en relación con otras áreas del país. Siguiendo el mismo criterio de Caracciolo de Basco \& Rodríguez Sánchez (1978) se define explotaciones campesinas desde el punto de vista operativo a todas aquellas unidades que poseen una cantidad determinada de tierra y sus límites varían en función de la ubicación espacial de las mismas, según departamentos ${ }^{2}$.

Para el año 2002 las EAPs campesinas registradas fueron 14.215, lo que representan un $67,80 \%$ del total provincial. Este último constituye un rasgo distintivo de la estructura agraria santiagueña, el fuerte peso y persistencia de explotaciones agropecuarias sin límites definidos, ya que para el año 2002 representaban el 48,30\% del total y se exhibe un incremento del $8,47 \%$ en relación al CNA del año 1988. Los regímenes de tierra relacionados a este tipo de explotación son los ocupantes de tierras privadas y fiscales; campos comuneros; aparcerías precarias y sucesiones indivisas. A partir del registro de las EAPs sin límites definidos se pudo reconocer un sujeto social agrario particular, el campesino con ánimo de dueño (Paz, 2006, 2013). Este sujeto realiza la ocupación precaria de tierra privada o fiscal, carecen de los títulos de propiedad y debido a que no existe delimitación precisa de las superficies, practican la cría a monte abierto de los animales y sólo construyen algunos cercos de ramas en las áreas de cultivo. Frente a la expansión de la frontera agropecuaria, dichas tierras se convierten en territorios en disputa, dando lugar a fuertes conflictos entre las empresas agrícolas, ganaderas y forestales con los poseedores tradicionales de esas tierras (Slutzky, 2008).

Además, la existencia de este tipo de explotaciones está estrechamente vinculada a la persistencia de formas de producción tradicionales cimentadas en la disponibilidad de amplias superficies de monte generalmente de uso compartido y el desarrollo de la

\footnotetext{
${ }^{2}$ Se considera explotaciones campesinas aquellas menores a 10 hectáreas que se ubican en la zona de riego y
} 100 hectáreas para aquellas establecidas en el área de secano. 
ganadería extensiva. Cabe resaltar que el mayor porcentaje de este tipo de explotaciones se encuentra localizada en áreas de secano (sin riego), con fuertes restricciones de acceso al agua y condiciones agroecológicas frágiles que ponen límites al desarrollo de la agricultura y explican en cierta medida la prevalencia de la actividad pecuaria como elemento clave en el despliegue de sus estrategias productivas de los campesinos ocupantes con ánimo de dueño.

Por otra parte, no es conveniente perder de vista que la estructura agraria expresa las relaciones de poder y luchas por la ocupación del espacio entre sujetos con distintas lógicas de territorialización, cuya contextualización responde a variables de larga duración y a dinámicas más recientes, como por ejemplo la expansión de la frontera agropecuaria, la extranjerización y el acaparamiento de tierras (Paz \& Jara, 2013). En efecto, el análisis de su conformación actual se torna inteligible en concomitancia con distintos procesos del pasado.

Antes de la conquista española, el asentamiento poblacional se organizó en la Mesopotamia del actual territorio de Santiago del Estero comprendida por el Río Dulce y El Salado, reconocida principalmente como una zona de emplazamiento del pueblo Jurí, más tarde llamado Lule y Tonocoté, los primeros identificados como pueblo nómade y de cazadores; mientras que los segundos como sedentarios y labradores (Farberman \& Taboada, 2012). Pero hacia el oriente se desarrollaba una economía basada en la recolección, la caza y la pesca (Paz \& Jara, 2013, 2014). Con la conquista y la colonización, las tierras de uso comunitario de la población nativa fueron objeto de la apropiación privada bajo diversas formas como mercedes reales y encomiendas, lo que no implicó la disolución de las formas de gestión mancomunada de la tierra. Farberman (2016) advierte que en Santiago del Estero durante los tiempos coloniales (principalmente entre los siglos XVII al

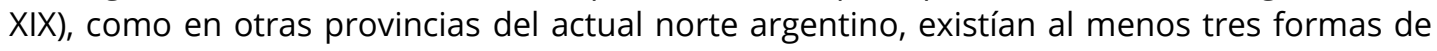
propiedad indivisa como: el mayorazgo, los pueblos indios y los campos comunes o mancomunados. Estos últimos también conocidos como mercedes, resultaban de la decisión de los herederos de no partir de la tierra. Destaca la funcionalidad de esta forma de poseer en ambientes áridos, donde tenían lugar prácticas agrarias colectivas ligada a la gestión de la tierra, montes y aguas por parte de un grupo de personas unidas por lazos de parentesco aunque con el tiempo las comuniones llegaban a ser suprafamiliares y no necesariamente involucraba relaciones sociales simétricas. A su vez, procesos como el reemplazo de las encomiendas por reducciones durante el siglo XVII y luego de fortines a estancias avanzado el siglo XVIII fueron delineando formas de ocupación del espacio por parte de los criollos articulados a amplias superficies de tierra sin delimitación precisa (Togo, 2005).

En la segunda mitad del siglo XIX, en el marco de la constitución del estado nacional y provincial y a raíz de la integración al mercado capitalista tuvo lugar la consolidación del latifundio a partir de un proceso de despojo de las poblaciones campesinas e indígenas de sus tierras. En las postrimerías del siglo XIX, la denominada colonización agraria, entendida como la ocupación de la tierra por inmigrantes extranjeros impulsada desde los gobiernos federales, abrió paso a un nuevo tipo de poblamiento y a una distribución de la tierra en cuadrículas bien definidas en sus límites. Sin embargo, este proceso tuvo un alcance restringido en Santiago del Estero y sus efectos sólo se advierten en la instalación de colonia en espacios reducidos como Selva, Malbrán, Pinto, Bandera, entre otras.

A mediados de 1930, la instauración del obraje en la provincia implicó el desarrollo en el monte santiagueño de un estilo de producción y ocupación territorial ligado a la expansión del ferrocarril en el territorio nacional que involucró la inversión de capitales extranjeros en la explotación de las especies maderables, especialmente el quebracho colorado (Guaglianone, 2001; Dargoltz, 2003) en los montes santiagueños. Tasso (2005: 126) señala que tanto la estancia como el obraje generaron "un régimen social rígido que fortaleció el vasallaje antiguo bajo formas capitalistas y consolidó estilos políticos de tipo patronal". Esa configuración social donde se articulan sistemas de servidumbre e integración a la economía de mercado mediante la producción primaria, constituyó la base de la estructura agraria santiagueña hasta la actualidad. 
Finalmente, hacia mediados del siglo XX, la explotación forestal perdió la rentabilidad y el saldo del retiro de los obrajes fueron la deforestación y la desocupación de la mano de obra que había sido absorbida por la explotación forestal capitalista. A pesar que muchos desocupados optaron por la migración, otros de los antiguos hacheros permanecieron en esas tierras desarrollando estrategias de reproducción vinculados a la producción agropecuaria dando lugar a procesos de recampesinización, aunque sin regularizar en los términos del código civil, sus posesiones de la tierra. La vulnerabilidad de estos campesinos sin títulos, expuestos a desalojos, se intensificó durante la década del sesenta, cuando grandes inversionistas eligieron las tierras fiscales del Chaco Santiagueño como foco de inversión para el algodón (Dargoltz, 2003). Estas situaciones de conflictividad agraria en torno a la tenencia de la tierra han proliferado como parte de la dinámica de procesos contemporáneos como el corrimiento de la frontera agro-ganadera, la extranjerización y el acaparamiento mundial de tierras (Paz \& Jara, 2013; Paz et al., 2015).

En suma, se aportan pistas que abonan la hipótesis sobre la reproducción social de pobladores rurales ocupantes con ánimos de dueño en el área de secano de Santiago del Estero al interior de las "unidades mayores" registradas bajo la categoría censal de explotaciones sin límites definidos. Tales procesos estarían ligados a formas de apropiación y gestión comunal de la tierra y recursos asociados (monte y agua), cuyos orígenes se remontan a las formas de posesión alternativas a la propiedad privada individual en el período colonial, pero que persisten hasta la actualidad sostenidas por un entramado de relaciones sociales. A continuación, se presentan algunas evidencias empíricas en las que se funda este supuesto a partir del estudio de caso en el paraje El Hoyo, localizado en el límite de los departamentos Figueroa y Moreno al noreste de la provincia, donde se desarrolla la experiencia de los encierros ganaderos y comunitarios.

\subsection{Una matriz comunal en el espacio rural santiagueño: monte común, ganadería y redes sociales}

Se utiliza la noción de matriz comunal para referir a un complejo de condiciones que revisten un carácter sine qua non en la estructuración de relaciones comunales. Es menester, identificar para cada caso de estudio cuáles serían estas condiciones, en la medida que resultan de procesos estructurales que tienen lugar en distintas escalas espaciales y temporales. En el caso del mundo rural de Santiago del Estero, podría decirse que los procesos que operaron en la conformación de la estructura agraria posibilitaron en cierta medida la configuración de matrices comunales. En particular, aquellos procesos que dieron lugar a la persistencia de amplias superficies de tierra y monte sin delimitación precisa, donde a lo largo del tiempo se fueron instituyendo modos de ocupación y apropiación basadas en el uso común de la tierra y recursos asociados.

La matriz comunal en El Hoyo, estaría dada al menos por tres condiciones. En primer lugar, la disponibilidad de amplias superficies de tierra, monte y otros recursos de uso común. En segundo lugar, la dotación pecuaria de los pobladores y el conjunto de prácticas llevadas a cabo por estos, las cuales se sustentan en el aprovechamiento de los bienes comunes en un escenario con características agroecológicas y socioeconómicas hostiles para el desarrollo de las fuerzas productivas. En tercer lugar, la movilización de un capital social, entendido como una compleja red de relaciones sociales que se configuran a partir del trabajo colectivo y las formas de apropiación de los comunes.

Formas sociales de producción en contextos de hostilidad

El paraje El Hoyo se localiza en la región del Chaco-semiárido que presenta un régimen de precipitaciones marcadamente estacional con concentración de lluvias en la época estival; una elevada evapotranspiración potencial anual que define un marcado déficit hídrico; una gran amplitud térmica con elevadas temperaturas estivales que ascienden más allá de los $48^{\circ} \mathrm{C}$. Por lo tanto, las alternativas productivas se ven limitadas y condicionadas por la disponibilidad y el acceso al agua, tanto para consumo humano, como para su aprovechamiento agrícola-ganadero (Arístide, 2009). En este paraje residen 65 familias emplazadas en aproximadamente 10.000 hectáreas, sus posesiones sin límites precisos 
abarcan grandes extensiones de monte, bajo formas de tenencia precaria de la tierra y donde existe un escaso desarrollo de infraestructura básica (vial y de servicios básicos como electricidad). Este espectro de condiciones restaron dinamismo al avance del sistema capitalista y al mismo tiempo favorecieron el despliegue de estrategias de supervivencia por parte del campesinado, las cuales se sustenta en prácticas culturales tradicionales (Paz, 2013).

Las principales actividades productivas se sostienen sobre la base del aprovechamiento del recurso monte, como la ganadería extensiva a monte y la extracción de madera de las distintas especies forestales especialmente quebrachos, algarrobo y mistol. Muchos de los pobladores de El Hoyo tienen un pasado como hacheros, empleados en los obrajes que operaban en zonas aledañas al ferrocarril. Como explica Arístide (2009) durante este período la "explotación forestal indiscriminada y la práctica asociada de ganadería extensiva de bovinos de carne y animales de tiro fueron moldeando el paisaje", que además de la reducción drástica de la masa arbórea y el aumento excesivo de la carga animal, devino en la evolución de algunos pastizales en matorrales (Arístide, 2009, p. 29).

En los períodos estivales, la mayor porción de la fuerza de trabajo familiar se ocupa de la ganadería bovina debido a que en esos meses coincide con los períodos de mayores precipitaciones, por lo que, en consecuencia incrementa la oferta forrajera natural y tienen a lugar la preñez, las pariciones y los destetes, tareas que implican mayor control de los rodeos bovinos. Contrariamente, en los períodos invernales cuando las precipitaciones disminuyen y la disponibilidad de agua también es escasa para el ganado, los niveles de mortandad animal ascienden. Durante estos meses de estación seca, la mayor parte de la fuerza de trabajo familiar se avoca a la extracción de leña del monte para la producción de carbón, período en que la demanda de este producto crece ya que es utilizado como principal material combustible en la zona.

Bienes naturales de uso común: monte, el agua y la tierra.

El monte constituye un recurso clave para las actividades que despliegan las familias pobladoras del paraje El Hoyo para su sostén. A pesar de las dificultades para rastrear los orígenes del uso compartido del monte, una práctica extendida entre vecinos residentes en la zona, algunos procesos favorecieron la apropiación ${ }^{3}$ del monte sin divisiones ni parcelamientos. Como sostiene Riat (2012), con el declive del modelo obrajero-forestal, tuvo lugar una relocalización de la población en áreas desmontadas por las empresas forestales y el advenimiento de un proceso de campesinización, ya que adoptaron prácticas de subsistencia como el desmonte y la ganadería basadas en el uso común de amplias superficies de monte, combinada con la producción para el mercado y las migraciones estacionales.

De esta manera, es posible advertir que la indivisión del monte, no constituye "un estado salvaje opuesto al civilizado, que disciplina el territorio en parcelas", al contrario, se trata de un "símbolo de lo interminable temporal y espacialmente, aquello que como el aire (al menos por ahora) no hace falta reclamar como propio" (Villalba et al., 2016, p. 82). Por consiguiente, existe cierta concomitancia entre actividades como la ganadería extensiva y el desarrollo de comunalidades en espacios rurales. Al respecto, Giménez Romero (1991) sostiene que ciertas actividades tales como "el aprovechamiento de los bosques, rastrojos y la ganadería extensiva requieren un manejo abierto y comunal debido a la existencia de ciertas barreras ecológicas" (Giménez Romero, 1991, p. 515-516). En el Hoyo, los rodeos de los pobladores deambulaban libremente a través del monte, pastoreando según la función y disponibilidad del forraje.

Otro de los recursos naturales de uso común, es el agua. Se trata de un aspecto crítico, ya que el paraje se encuentra en área de secano y con grandes dificultades para el acceso y la provisión de este recurso. Por esta razón, para procurar su acceso los pobladores de El

3Utilizamos el término apropiación en el sentido que le imprimen Toledo \& Barrera Bassols (2008), un proceso de apropiación, es "la forma particular en que cada familia reconoce, asigna y organiza sus recursos productivos, su trabajo y su gasto monetario con el objeto de mantener y reproducir sus condiciones materiales y no materiales de existencia". 
Hoyo aportan mano de obra familiar y materiales para la construcción y mantenimiento de reservorios de agua de lluvia para consumo familiar (aljibes, cuya capacidad oscila entre 2.000 y 10.000 litros de agua) y animal (represas o aguadas) que son de uso compartido entre familiares y vecinos. Los aljibes comunitarios, se encuentran presentes en la escuela y en la capilla católica localizadas en el paraje.

\section{Redes de relaciones: algunas características del trabajo comunal}

El punto de partida para entender por qué ciertos recursos revisten un carácter comunal es considerar las redes de relaciones entre quienes están implicados en el uso y apropiación de un acervo de bienes en relación a intereses políticos y morales específicos. Retomando los planteos de Giménez Romero (1991), la "pertenencia a la comunidad es la clave para acceder a los recursos comunes que detentan". Por consiguiente, en determinadas instancias, la calidad de miembro de la comunidad concede al individuo un "entramado de derechos y obligaciones de uso y aprovechamiento" (Giménez Romero, 1991, p. 484). En esta dirección, Bollier (2008) admite que no es posible definir bienes comunes independientemente del grupo o la comunidad específica que tiene su control y manejo como tampoco de los valores y tradiciones en torno a los que construyen una identidad y posibilitan su autogobierno.

Los vecinos, comuneros en El Hoyo se convierten en coapropiadores de los bienes comunes previamente mencionados. De esta manera se va generando vínculos de interdependencia que exceden los límites físicos de la comunidad, puesto que como ellos sostienen la "responsabilidad con la comunidad está más allá de vivir o no aquí" (Comunera de El Hoyo, 40 años).

Las actividades principales de la comunidad requieren del trabajo colectivo. En relación a la ganadería extensiva, una práctica extendida es el préstamo de reproductores entre los pobladores de El Hoyo, principalmente se lleva a cabo en las épocas de servicio que se retribuye generalmente con productos (provisión de maíz o terneros a medias) y con jornales de trabajo. Además, la faena de los animales, en especial los vacunos, constituye un ritual familiar en el que participan distintos vecinos de la comunidad además de los miembros de la familia y se distingue una división de tareas. Los hombres procuran el afilado de chuchillos, atajar y enlazar los animales para luego realizar la faena. Mientras que las mujeres realizan la limpieza y lavado de las vísceras y menudencias, desde la sangre hasta los intestinos, para su preservación y aprovechamiento con distintos fines culinarios.

Respecto a la producción forestal, se observa una red de relaciones construidas alrededor del intercambio de saberes en torno a la selección de las especies para aprovechamientos diferenciales como la leña o para elaboración de poste o carbón. Además, en la producción de carbón, las mujeres y niños se involucran en la recolección de la madera del monte, mientras que tareas como la carga y el manejo de los hornos a cargo de los hombres conlleva requerimientos de mano de obra que exceden la disponibilidad de fuerza de trabajo familiar y por lo que se contratan a vecinos a quienes se les retribuye con maíz o bien una porción de la producción.

De manera simultánea con estos procesos, se establecen lazos de interdependencia entre los comuneros que traspasan el ámbito productivo y se materializan en torno al uso, gestión, preservación y mantenimiento de los bienes comunes. En este espacio socialmente construido, los actores se enfrentan para tener acceso al intercambio, junto con la conservación y la transformación de la fuerza vigente en el campo, en torno a la gestión de un recurso de uso común (Bourdieu, 2002). Empero, a diferencia de la concepción capitalista utilitaria, los sistemas comunales se encuentran insertos en una economía moral (Thompson, 1974), basados en comportamientos económicos que se definen a partir de valores o creencias distintos a la presunta racionalidad instrumental del homo economicus. De esta forma, los enfrentamientos en torno a los recursos, se sustentan en principios de reputación, de satisfacción de necesidades básicas (el valor de uso), reciprocidad, preferencias de relaciones comerciales con vecindad y parentesco, entre otras.

Por consiguiente, los elementos funcionales sobre los cuales se erigen las prácticas comunales en la apropiación de los bienes comunes son aquellos vinculados a la 
construcción del consenso-acuerdo, la organización del trabajo, el desarrollo de un diseño institucional del sistema comunal, los principios éticos-morales compartidos $y$, las actividades de esparcimiento que les son comunes.

Otro elemento funcional de la matriz comunal son los mecanismos de organización del trabajo. A diferencia de la concepción capitalista donde el valor del trabajo se fija en el mercado, el trabajo comunal incluye de manera contradictoria y complementaria la idea de empleo y trabajo creativo, como obligación y como posibilidad, es decir una actividad abierta a la invención (Osorio, 2013). Los criterios de distribución de funciones en un sistema comunal son múltiples y, en muchas ocasiones se encuentran yuxtapuestos. En El Hoyo, las tareas administrativas vinculadas a créditos, subsidios, como así también la presentación de notas y proyectos junto con la atención primaria de la salud de la comunidad se encuentran a cargo de las mujeres. La limpieza de los caminos, el mantenimiento del jardín de infantes y la escuela primaria se encuentra a cargo del grupo de hombres que participan en la cooperadora de la escuela y algunos en la Asociación de fomento comunal.

En lo que respecta al diseño institucional de un sistema comunal, es posible identificar pautas organizativas a nivel consuetudinario y/o a nivel de estatutos escritos, con la consagración de una estructura de órganos con división de funciones y medios para la resolución de conflictos. El Hoyo consta de un estatuto y un reglamento de funciones que debe cumplir cada socio perteneciente a la Asociación de fomento comunal de la comunidad, no obstante las jerarquías fuera de lo reglado, se establecen en función de antigüedad en la comunidad, tamaño del rodeo, cantidad de familiares que habitan de manera permanente en la comunidad, oficio o trabajo principal (albañil, mecánico, productor de carbón, tenedor de hacienda, maestro, policía, entre algunas).

Por último, en los sistemas comunales se despliegan múltiples prácticas no económicas ligadas al esparcimiento de los comuneros, como ser la organización de campeonatos de futbol entre los sectores norte y sur del Hoyo, loterías, rifas y bingos para recaudar fondos para la organización. La construcción de identidades como el desarrollo de capacidades y de liderazgos genera un sentimiento de "un orgullo por todavía vivir del monte con mi familia" (Comunera de El Hoyo, 65 años).

Por consiguiente, el mancomún y las relaciones de "adentro" no es algo dado o preexistente al régimen actual, sino más bien es un proceso de construcción cotidiana que aparece cuando la tierra es convertida en territorio al ser co-habitada de una forma peculiar (Osorio, 2013).

\subsection{Diseños de organización social de la producción anclados en la matriz comunal: encierro comunitario y ganadero.}

\section{Conflictividad y acción colectiva en defensa de la tierra comunal}

En el año 2004, a raíz de un enfrentamiento con una empresa de origen extraprovincial que compra un campo colindante con la tierra en posesión ${ }^{4}$, las familias de El Hoyo desplegaron una batería de acciones colectivas orientadas a frenar el despojo de sus tierras que incluía la acción directa en el conflicto impidiendo el avance de las topadoras y más tarde el montaje de las carpas en los lugares de conflicto, como también apelar a denuncias y trámites judiciales. Diversas fueron las tácticas de desalojo por parte de la empresa, desde denuncias penales en contra de los pobladores acusándolos de delito de usurpación, la ruptura de alambres que delimitaban la tierra en posesión, desmonte y amedrentamiento de la población con fuerzas de seguridad privada contratadas por los empresarios.

\footnotetext{
${ }^{4}$ Según un estudio del Observatorio de Derechos Humanos de las Comunidades Campesinas de la Subsecretaría de Derechos Humanos de la provincia de Santiago del Estero, entre el año 2004 y el año 2011 se registraron unos 420 reclamos por conflictos producidos a raíz del problema de tierras que ascienden a 475.101 hectáreas.
} 
El reconocimiento de la Mesa de Tierra del departamento Figueroa ${ }^{5}$ y el Movimiento Campesino de Santiago del Estero (MOCASE) como organizaciones que intervienen en la defensa del derecho a la tierra de campesinos e indígenas en el marco de sus disputas con empresarios y terratenientes, conduce a los pobladores de El Hoyo a intervenir en esos espacios. Por otra parte, extensionistas del ex-Programa Social Agropecuario (a partir de aquí, PSA), habían comenzado a intervenir en el paraje con la intención de alentar la producción bovina; sin embargo no permanecieron al margen del conflicto por la tierra. Las propuestas de mejorar la producción comenzó a ser legitimada desde el discurso del derecho posesorio enarbolado por las organizaciones de base campesina que operaban en el territorio bajo el argumento que la vía para afianzar la posesión sería la implementación de mejoras productivas.

Dado que los pobladores de El Hoyo realizaban cría a monte de animales, la pérdida y robo del ganado eran frecuentes. Los técnicos del PSA al advertir estas problemáticas, proponen la conformación de encierros ganaderos o potreros, es decir superficies de monte alambradas y destinadas a la cría de ganado bovino para lograr un mayor control del rodeo y uniformidad en la oferta ganadera mediante prácticas de manejo silvo-pastoril. EI PSA preveía asistencia técnica y financiera para llevar adelante estos emprendimientos productivos asociativos. Los pobladores conformaron dos grupos que estarían a cargo de la gestión de potreros localizados al sur y al norte del campo comunal.

El enfrentamiento con la empresa aconteció cuando los pobladores de este paraje trabajaban en la delimitación del portero sur. Frente a la amenaza de ser despojados de esas tierras, muchos pobladores adhieren a la iniciativa de construir los potreros y cerrar el campo comunitario para de este modo defender la tierra. Al respecto, es posible advertir el inicio de los potreros, en un fragmento del relato de uno de los pobladores:

“Se venían los empresarios de allá (del sur) entonces nosotros ya veíamos que no íbamos a tener tierra y qué es lo que hemos hecho nosotros [...] como para hacer posesión hemos hecho los potreros nosotros" (Poblador de El Hoyo, socio de un encierro).

Por otra parte, los técnicos del PSA que intervienen en la zona sostienen que la propuesta de los encierros ganaderos surge de las necesidades de la población. Aunque reconocen que se trata de una iniciativa, que no sólo respondía a objetivos económicos-productivos de los pobladores de El Hoyo como lograr mayor control del rodeo en épocas de pariciones y evitar el robo; también admiten la necesidad de evitar el desalojo y defender la tierra que ocupan haciendo posesión. Asimismo, llevar adelante esta iniciativa implicaba captación y refuncionalización de los recursos emanados de distintos programas estatales, nacionales y provinciales, que financiaban inversiones prediales individuales (y no comunitarias) con fines productivos. Así lo pone de manifiesto un técnico del PSA con su relato:

“Defender haciendo posesión, a través de mejoras en la producción, esa es la propuesta que hace la secretaría para afrontar la problemática de la tenencia la tierra y los conflictos generados en torno a eso" (Técnico del PSA).

En el vínculo técnicos extensionistas-pobladores rurales se gesta y desarrolla una estrategia de defensa de la tierra basada en el binomio 'producir-hacer posesión'. Dicha estrategia se sustenta en el discurso de derecho posesorio sobre la tierra, promovido por las organizaciones que asumen la representación de campesinos e indígenas, pero que se despliega a través de propuestas técnico-productivas promovidas desde la institucionalidad pública. No obstante, con la conformación de los encierros ganaderos entran en tensión lógicas y prácticas de gestión de los recursos de uso común no sólo entre los técnicos extensionistas con los pobladores de El Hoyo, sino también entre estos últimos.

\footnotetext{
${ }^{5}$ Las Mesas de Tierras son organizaciones que tienen su origen asociado a la intervención de la pastoral social de la Iglesia Católica en poblaciones rurales, pero que en la actualidad participan además de los representantes de las comunidades eclesiales de base, organizaciones gubernamentales que realizan extensión rural, como también delegados del Movimiento Campesino de Santiago del Estero.
} 
Los encierros ganaderos en sí: una iniciativa productiva apara afianzar la posesión comunal

Con la conformación de los encierros ganaderos en El Hoyo se propiciaron cambios en los siguientes aspectos: a) el desarrollo de la práctica productiva de la cría bovina b) en el stock y composición de la base de recursos comunes; c) pero también en los modos de uso y gestión de dichos recursos. Gran parte de estos cambios fueron propiciados a partir de los vínculos entre pobladores del paraje y técnicos del PSA, que proporcionaron asistencia técnica, pero también les facilitaron el vínculo con otros organismos públicos nacionales y provinciales ejecutores de programas estatales como PROINDER ${ }^{6}$ y PROCARNE ${ }^{7}$.

En relación a los cambios en la práctica productiva de la cría, cabe resaltar que durante la implementación de estos últimos programas, los pobladores de El Hoyo efectuaron la compra de dos reproductores; la aplicación de un plan de sanidad animal; la compra de insumos para siembra de pasturas; contratación de servicios de maquinaria agrícola y la adquisición de instalaciones ganaderas e infraestructura productiva. Así reflexiona un socio sobre las mejoras en la producción desde que emprendieron esta iniciativa:

“Hemos mejorado la cría...después bueno teníamos como pastura que era distinto a lo que era antes al natural...y ahora tenemos en el potrero todo lo que es instalaciones (...) corrales, bebederos y ahora vamos a empezar a tirar agua del pozo". Poblador del paraje El Hoyo (38 años)

Respecto a la organización social de la producción, inicialmente se conformaron dos grupos de productores integrados por 13 y 12 socios respectivamente que realizaron la clausura de dos lotes ambos que abarcan una superficie de 736 hectáreas. A través del proyecto financiado por PROINDER se implementó en el primer potrero un sistema silvopastoril que implicó el rolado selectivo de especies forestales, la siembra de variedades megatérmicas $^{8}$ en un lote de 120 hectáreas y la preservación de pastos naturales para forraje. Mientras que en el segundo potrero sólo se sembró una superficie de 44 hectáreas.

Durante la implementación de estos programas estatales, los vínculos con los técnicos les permitieron no sólo aumentar el stock y diversificar la composición de recursos de uso común, sino también dio lugar a la institucionalización no-formal de acuerdos respecto al uso y gestión de esos bienes de propiedad colectiva entre los usuarios. En gran parte estos acuerdos estaban basados en las recomendaciones técnicas para el manejo sustentable de los recursos del sistema, tales como la fijación de una cuota de animales por socio dentro del encierro en función de la capacidad de carga animal estimada. Además entre los socios se establecieron acuerdos socio-organizativos como pautas y turnos de trabajo para tareas vinculadas al cuidado de rodeo entre los hombres de las familias socias, mientras que las mujeres realizaban tareas vinculadas con la gestión y la rendición de proyectos ante los organismos públicos que brindaron financiamiento.

La institucionalización de estos arreglos no fue un proceso espontáneo y exento de tensiones entre los socios, como en su relación con técnicos y otros agentes estatales. En este aspecto se hacen eco los planteos de Ostrom (2000) en torno a la sostenibilidad de los sistemas de recursos de uso común en relación a la capacidad de los usuarios para crear sus propios mecanismos de comunicación y control en el ejercicio del derecho a la propiedad colectiva y para garantizar su protección.

\footnotetext{
${ }^{6}$ Programa de Desarrollo de Pequeños Productores Agropecuarios (PROINDER) tuvo alcance nacional y comenzó a ejecutarse en el año 1998. Su objetivo fue mejorar las condiciones de vida de pequeños productores agropecuarios y trabajadores rurales transitorios promoviendo mejoras en sus ingresos, en su organización y participación a través de inversiones en asistencia técnica, capacitación apoyo en la comercialización y fortalecimiento institucional.

${ }^{7}$ Programa Ganadero de la Provincia de Santiago del Estero (PROCARNE) dependiente del Ministerio de Producción, Recursos Naturales, Forestación y Tierras de la provincia que tiene por objetivo aumentar el aporte de la ganadería bovina para carne en el Producto Bruto Geográfico, prevé distintas estrategias de intervención como: asistencia financiera, producción, industria, comercialización, seguridad jurídica-sanitaria, como también capacitación y extensión.

${ }^{8}$ Se trata de especies forrajeras que se adaptan a suelos salinos y/o alcalinos, con limitada retención de la humedad y que pueden desarrollarse en áreas con déficit hídrico, características agroecológicas que presenta la zona de secano de la provincia de Santiago del Estero.
} 
Al mismo tiempo que impulsaban cambios técnicos-productivos, los extensionistas del PSA promovían el 'asociativismo' y "la organización comunitaria" en la gestión de la actividad de cría. Partían del diagnóstico que impulsar la cría de forma mancomunada era una propuesta viable, en tanto se asentaba en la práctica de uso compartido del monte para pastoreo. Así surgieron dos grupos de productores para la gestión de los encierros y también la formalización de este agrupamiento que derivó en la conformación de la asociación de fomento comunal que aglutinaba a los pobladores del paraje a cargo de la gestión de ambos potreros. Con la constitución de la asociación nacía un sujeto colectivo que operaba como interlocutor ante los agentes estatales, un rol que le asignaban tanto los técnicos como los socios.

No obstante, la existencia de una asociación no suponía la anulación de las rivalidades preexistentes entre sus miembros, por el contrario los antagonismos se cristalizaron y se profundizaron en torno a las decisiones sobre el uso y gestión de los recursos comunes, tanto del monte como aquellos obtenidos a partir de los proyectos productivos. Cuando la intervención de los técnicos se orientó a la promoción de la ganadera bovina y la iniciativa de cercar el perímetro de 10.000 hectáreas de monte, quienes carecían de animales propios y se dedicaban sólo a la extracción forestal, veían menguar las posibilidades de reproducir una actividad como la fabricación y venta de carbón que tiene un retorno más rápido en términos de ingresos monetarios respecto de la ganadería. Estas tensiones ponen en relieve la oposición de intereses entre hacheros y ganaderos respecto al aprovechamiento del monte de uso comunitario.

\section{A modo de cierre}

En el campo de las ciencias sociales abundan los estudios sobre sistemas comunales y campesinos entre los que se advierten por un lado interpretaciones idílicas de "lo rural" y "Io indígena" y por otro, visiones peyorativas e incluso apocalípticas sobre su devenir. Desde estas tendencias analíticas las comunalidades rurales han sido enaltecidas como unidades naturales y herencia vívida de los pueblos originarios, o bien denostadas como residuo de sociedades primitivas y condenadas a la pobreza. Entre estas interpretaciones subyacen los supuestos sobre su incapacidad, ineficiencia e inviabilidad.

En efecto, el desafío consiste en no quedar entrampados en los romanticismos o en los pesimismos exacerbados. Para sortear estos sesgos, como también los riesgos analíticos que suponen privilegiar las condiciones estructurales y descuidar las condiciones de la agencia o viceversa, se buscó integrar el abordaje de la estructura agraria de Santiago del Estero y los procesos que la moldearon, junto con las prácticas de los actores. La categoría de matriz comunal que se propone en este trabajo apunta a captar y denotar las condiciones estructurales sobre las que se asientan las prácticas de los actores en la configuración de relaciones comunales. Al mismo tiempo, se da cuenta de su articulación con el conjunto de prácticas que se despliegan en distintos ámbitos de la vida cotidiana.

En esta línea, la propuesta es entender estas formas de organización social agraria como comunalidades rurales, es decir como formas de relación social basadas en la re-producción de "lo común", que se expresan y efectivizan en instituciones y en las prácticas colectivas agrarias. Aprehender las comunalidades en términos relacionales, implica analizar cómo se (re)produce lo comunal en los modos de vinculación entre los/as pobladores rurales y actores que se desempeñan en otros dominios de la vida social como el estatal o el religioso. Asimismo, se reconocen dos dimensiones de esta relación social: una comunalidad objetivada, que involucra a las condiciones materiales sobre las que se estructuran ciertas prácticas, por ejemplo la cría de ganado a campo abierto es una práctica productiva que se asienta en la disponibilidad de bienes y/o recursos susceptibles de apropiación comunal, como la tierra y el monte. Por otra parte, una comunalidad incorporada, refiere a un sentido de pertenencia construido por un grupo que toma lugar en varias bases (Brow, 1990), como por ejemplo un pasado compartido de lucha por la tierra. La distinción entre estas dimensiones no es fáctica sino que responde a fines analíticos y requieren ser abordadas y articuladas una a la otra. 
La significatividad de la experiencia de los encierros ganaderos y comunitarios para analizar la estructuración de comunalidades rurales en Santiago del Estero puede señalarse al menos en dos sentidos. Por un lado, la ganadería extensiva tiene una centralidad en las estrategias de reproducción social de los pobladores del paraje y de su saber-hacer ligada a esta actividad, cuya práctica está en estrecha relación con la disponibilidad de amplias superficies de tierra y ciertas condiciones agroecológicas frágiles para el despliegue de la agricultura. La conformación de encierros ganaderos de gestión asociativa es una iniciativa productiva congruente con la práctica del uso común del monte y el agua en campos sin límites precisos, como también del aprovechamiento de los recursos pecuarios. No obstante, implicó una redefinición de los usos de los recursos comunes y un (re)diseño de la organización social de la producción en ganadería a partir de la intervención de los técnicos extensionistas.

Por otra parte, los conflictos por la tenencia de la tierra comunal y la intervención de agentes estatales en la implementación de programas de desarrollo rural suscitan reflexiones sobre las potencialidades de estas formas de organización social agraria para la emergencia de iniciativas alternativas al desarrollo rural. Cabe destacar que ante el peligro del despojo de las tierras en posesión comunal se refuerza el sentido de comunidad, en términos de sentido de pertenencia en el afán por defender un recurso que se encontraba bajo el control exclusivo de los pobladores del paraje. Esto se ve reflejado en las prácticas de producción simbólica de la comunidad, en los procesos de representación política con la designación portavoces para intervenir en otras organizaciones campesinas o bien con la creación de una asociación de fomento comunal que permitió su reconocimiento como sujeto colectivo al asumir el rol de mediadora especialmente en su relación con agentes estatales. Cabe subrayar, el rol de las agencias estatales en la promoción de estas comunalidades para superar situaciones de pobreza rural. A través de los vínculos con técnicos extensionistas que operaban en el PSA, los pobladores rurales pudieron ampliar su base de recursos de uso común al captar recursos de provenían de la institucionalidad pública para incorporar y mejorar infraestructura productiva y de servicios para la población. Además, los técnicos promovieron prácticas de manejo ganadero y de los recursos del monte, capacidades de gestión y formalización de formatos asociativos de organización social que fueron adoptadas por los pobladores involucrados en los encierros, aunque de manera parcial o fragmentaria debido a las disonancias entre las proyecciones y tensiones de intereses no sólo con los técnicos, sino entre ellos mismos.

De la advertencia de estos aspectos se desprenden las siguientes cuestiones. Primero, los cambios en las prácticas de uso y gestión de los recursos de uso común y de vinculación con agentes estatales, también implicó la trasmutación de matriz comunal de El Hoyo. Estas mutaciones se observan en la ampliación del sistema de recursos comunes, la asociación de productores para administración de los encierros ganaderos, como también en la extensión de las redes de inter-reconocimiento y inter-conocimiento más allá de los lazos de parentesco y vecindad y sus beneficios en términos de acumulación de capital social. Segundo, los conflictos entre pobladores rurales y con los técnicos, ponen al descubierto por un lado, la heterogeneidad de objetivos y proyectos que incluso llegan a ser antagónicos, y por otro, la existencia de diferenciación social-económica entre los comuneros, aunque este aspecto no se aborda en profundidad aquí. Tercero, los agentes estatales producen a la comunidad en tanto la definen como sujeto-objeto de sus intervenciones, a partir de los supuestos cognitivos que responden en gran medida a los imperativos de las organizaciones en las que operan, como de sus trayectorias profesionales y de vida.

Por último este caso de estudio también es significativo en relación al debate sobre sistemas comunales y las posibilidades de desarrollo. Estas discusiones se revitalizaron en el escenario de América Latina debido a que se han documentado experiencias que ponen en relieve la persistencia de estas formas de organización social agraria ante el avance de los procesos de privatización y mercantilización sobre sus recursos, como también a los balances poco alentadores sobre los impactos de reformas agrarias, proyectos colectivistas y programas de modernización agraria. Mayer (1996), al reflexionar sobre la relación entre propiedad comunal y desarrollo en Perú señala el rol protagónico de las comunidades 
rurales en la gestión de las soluciones a sus problemas y en el manejo de sus recursos para lograr un desarrollo autosostenido, especialmente en una alianza estratégica con el estado, ya que reconoce su capacidad de organizarse y autogobernarse. También el documento de EMBRAPA editado por Eidt \& Udry (2019), titulado Sistemas Agrícolas Tradicionais no Brasil, da cuenta de quince experiencias donde reconoce formas de producción agrícolas acordes a la naturaleza, utilizando prácticas adoptadas por los pueblos y comunidades tradicionales con base comunal. Se resalta en ese documento que la Organización de las Naciones Unidas para la Alimentación y la Agricultura (FAO) reconoce a esos sistemas agrícolas tradicionales como patrimonio agrícola mundial buscando visibilizar las prácticas llevadas por sus pobladores.

En esta dirección, el caso analizado en este trabajo también permite visibilizar la agencia de los pobladores rurales para mejorar sus condiciones de existencia, mediante el aprovechamiento de recursos comunales y re-funcionalizar las prestaciones emanadas de la institucionalidad estatal en función de objetivos comunes. Además, se da cuenta de la capacidad de los agentes estatales para reajustar los imperativos organizacionales de intervención a los objetivos y modos de vida de los pobladores rurales y anclar sus propuestas a la matriz comunal existente, promoviendo algunas mutaciones en ella a partir de sus prácticas.

En Argentina y específicamente en Santiago del Estero, aunque la propiedad comunal no tenga reconocimiento en el orden jurídico formal, es una de las formas de ocupación-posesión de la tierra instituida entre sectores de la población rural y en la que se sustenta sus modos de vida. La omisión de esta situación ha impedido el diseño de políticas públicas específicas que tiendan a impulsar, sostener y desplegar su potencial sobre la base de los recursos disponibles, las capacidades sociales y en consonancia con los proyectos y valores compartidos por los comuneros.

Finalmente, este abordaje conceptual propuesto para entender las diversas formas de vida de los pueblos y comunidades tradicionales y campesinas en sus propios territorios, integrando en el análisis las formas de producir, de hacer y las cosmovisiones particulares, permite pensar en posibles desarrollos alternativos al planteado por el modelo del agronegocio y en políticas públicas acordes a una lógica que responda a esas matrices comunales.

\section{Referencias}

Arístide, P. (2009). Procesos históricos de cambio en la apropiación del territorio en Santiago del Estero (Chaco semiárido, Argentina): la reconstrucción del dique Figueroa. Revista Brasilera de Agroecología, 4(1), 1788-1891.

Barkin, D., \& Lemus, B. (2015). Construyendo mundos pos-capistalistas. Cultura y Representaciones Sociales, 10(19), 26-60.

Bollier, D. (2008). Bienes comunes: un sector soslayado de la creación de riqueza. In S. Helfrich (Ed.), Genes, Bytes y Emisiones: Bienes comunes y ciudadanía (pp. 30-41). México: Fundación Heinrich Boll.

Bourdieu, P. (2002). Las estructuras sociales de la economía. Buenos Aires: Manantial.

Brow, J. (1990). Notes on community, hegemony and uses of the past. Revista Digital Anthropological Quarterly, 63(1), 1-6. Recuperado el 15 de noviembre de 2010, de http://www.jstor.org/stable/3317955

Bustamante, M. (2010). La estructura agraria y su dinámica reciente: reflexiones sobre su abordaje. In Ponencia Presentada en Las III Jornadas del Doctorado en Geografía: Desafíos Teóricos y Compromiso Social en la Argentina de Hoy. La Plata, Argentina.

Caracciolo de Basco, M., \& Rodríguez Sánchez, C. (1978). El minifundio en la Argentina. Buenos Aires: Secretaría de Agricultura y Ganadería.

Dargoltz, R. (2003). Hacha y quebracho: historia ecológica y social de Santiago del Estero. Santiago del Estero: Ediciones Visozo Libros.

De Dios, R. (2012). Ordenamiento territorial e inclusión social en Santiago del Estero. Realidad Económica, 268, 112-127.

De Dios, R., \& Williams, J. (1998). Sistemas productivos y organización campesina. In A. Tasso \& R. Paz (Eds.), Tipologías y vida campesina. Santiago del Estero: Barco Edita. 
Eidt, J., \& Udry, C. (2019). Sistemas agrícolas tradicionais no Brasil (Coleção Povos e Comunidades Tradicionales, No. 3). Brasilia: EMBRAPA.

Farberman, J. (2006). Recolección, economía campesina y representaciones de los montaraces en Santiago del Estero, siglos XVI a XIX. Prohistoria, 10, 11-26. Recuperado el 14 de septiembre de 2016, de http://www.scielo.org.ar/pdf/prohist/v10/v10a01.pdf

Farberman, J. (2016). El Mancomún en Santiago del Estero entre la colonia y el siglo XIX. Historia y fundamentos de un problema de investigación. Indoamerica, 5, 13-36.

Farberman, J., \& Taboada, C. (2012). Sociedades indígenas del territorio Santiagueño: apuntes iniciales desde la arqueología y la historia: período prehispánico tardío y colonial temprano. Runa, 33(2), 113-132. Recuperado el 20 de enero de 2016, de http://revistascientificas.filo.uba.ar/index.php/runa/article/view/343/320

Flores, A. C., Villarreal, L. Z., Cruz Jiménez, G., \& Vargas Martínez, E. (2014). Economía social, comunalidad: orientación teórica para el turismo rural, como alternativa de desarrollo. Revista Mexicana de Ciencias Agrícolas, 5, 1645-1658.

Fuente Carrasco, M. E. (2009). Nueva ruralidad comunitaria y sustentabilidad: contribuciones al campo emergente de la economía-ecológica. Revista Iberoamericana de Economía Ecológica, 13, 41-55.

Fuente Carrasco, M. E. (2012). La comunalidad como base para la construcción de resiliencia social ante la crisis civilizatoria. Polis, 11(33), 195-218.

García Linera, A. (2009). La forma comunidad del proceso de producción: formas comunales que han precedido al régimen del capital: algunas determinaciones de forma y contenido técnicoorganizativo. In A. García Linera (Ed.), Forma valor y forma comunidad: aproximación teóricaabstracta a los fundamentos civilizatorios que preceden al Ayllu Universal (pp. 231-367). La Paz: CLACSO, Muela del Diablo Editores, Comuna.

Giménez Romero, C. (1991). Valdelaguna y Coatepec: permanencia y funcionalidad del régimen comunal agrario en España y México. Madrid: Ministerio de Agricultura, Pesca y Alimentación.

Grzebieluka, D. (2012). Por uma tipologia das comunidades tradicionais brasileiras. Revista Geografar, 7 , 116-137.

Guaglianone, A. (2001). Análisis y evaluación de impacto del modelo de desarrollo obrajero-forestal en el Chaco Santiagueño: el caso de los Juríes. In XXIII International Congress of the Latin American Studies Association. Washington.

Guerra Brayner, N. (2019). Da roça à mesa: caminhos e sentidos da patrimonialização do Sistema Agrícola Tradicional do Rio Negro, AM. In J. S. Eidt \& C. Udry (Eds.), Sistemas agrícolas tradicionais no Brasil (Coleção Povos e Comunidades Tradicionais, No. 3, pp. 29-54). Brasilia: Embrapa.

Gutelman, M. (1978). Estructuras y reformas agrarias. Barcelona: Editorial Fontamara.

Martínez Luna, J. (2015). Conocimiento y comunalidad. Bajo el Volcán, 15, 99-112.

Marx, K. (1986). El capital: tomo I: el proceso de producción de capital. México, Siglo Veintiuno.

Mayer, J. (1996). Propiedad comunal y desarrollo. In Congreso de la República del Perú. Recuperado el 10 de septiembre de 2016, de http://www.andes.missouri.edu/andes/Especiales/EM_Congreso.html

Osorio, A. (2013). La comunalidad como herramienta: una metáfora espiral. Cuaderno del Sur, 34, 39-55.

Ostrom, E. (2000). El gobierno de los comunes: la evolución de las instituciones de acción colectiva (1. ed.). México: Fondo de la Cultura Económica.

Palomeque, S. (1992). Los esteros de Santiago. Acceso a los recursos y participación mercantil. Santiago del Estero en la primera mitad del siglo XIX. Data, 2, 9-61.

Paz, R. (2006). ¿Desaparición o permanencia de los campesinos ocupantes en el noroeste argentino? Evolución y crecimiento en la última década. Canadian Journal of Latin American and Caribbean Studies, 61(31), 169-197. http://dx.doi.org/10.1080/08263663.2006.10816894

Paz, R. (2011). Agricultura familiar en el agro argentino: una contribución al debate sobre el futuro del campesinado. Revista Digital European Review of Latin American and Caribbean Studies, (91), 49-70. http://dx.doi.org/10.18352/erlacs.9242

Paz, R. (2013). Explotaciones sin límites definidos y desarrollo rural en Santiago del Estero: hacia un ordenamiento territorial. Realidad Económica, 277, 109-128.

Paz, R., \& Jara, C. (2013). Las nuevas dinámicas de los antiguos conflictos de tierra en regiones extrapampeanas. Revista Digital Voces en el Fénix, 17, 34-43. Recuperado el 20 de julio de 2014, de http://www.vocesenelfenix.com/sites/default/files/pdf/03_10.pdf 
Paz, R., \& Jara, C. (2014). Estructura agraria en Santiago del Estero: el proceso de territorialización de las explotaciones sin límites definidos y su tensión frente al avance del capitalismo agrario. Revista Digital Estudios Rurales, 4(6), 81-99. Recuperado el 2 de julio de 2015, de http://ppct.caicyt.gov.ar/index.php/estudios-rurales/article/view/1910

Paz, R., Lipshitz, H., Zerda, R., \& Tiedeman, J. (2015). Estructura agraria, áreas de concentración de la agricultura familiar y procesos de expansión de la frontera agropecuaria en Santiago del Estero, Argentina. Revista NERA, 18, 259-279. Recuperado el 13 de noviembre de 2015, de http://revista.fct.unesp.br/index.php/nera/article/view/3383

Raimbert, C. (2013). La ruralidad quilombola cuestionada o los nuevos desafíos de la agricultura familiar en Brasil. Revista Pueblos y Fronteras Digital, 7(14), 48-80. http://dx.doi.org/10.22201/cimsur.18704115e.2012.14.99

Riat, P. (2012). Conocimiento campesino, el "monte santiagueño" como recurso forrajero. Revista Digital Trabajo y Sociedad, 19, 477-491. Recuperado el 30 de agosto de 2015, de http://www.unse.edu.ar/trabajoysociedad/19\%20RIAT\%2monte\%20santiagueno\%20recurso\%20for rajero.pdf

Slutzky, D. (2008). Situaciones problemáticas de tenencia de la tierra en Argentina. Buenos Aires: Secretaría de Agricultura, Ganadería, Pesca y Alimentos. Recuperado el 3 de mayo de 2010, de http://redaf.org.ar/wp-content/uploads/2008/08/problematicas-de-tenencia-de-la-tierra.pdf

Stavenhagen, R. (1969). Las clases sociales en las sociedades agrarias. México: Siglo Veintiuno.

Tasso, A. (2005). Vida humana y organización social en condiciones de escasez. In A. N. Giannuzzo, M. E. Ludueña \& P. Araujo (Eds.), Santiago del Estero: una mirada ambiental. Santiago del Estero: Universidad Nacional de Santiago del Estero.

Thompson, E. (1974). La Economía moral de la multitud en la Inglaterra del Siglo XVIII. Revista de Occidente, 133, 54-125.

Togo, J. (2005). Asentamientos humanos y aprovechamiento de los recursos en Santiago del Estero. In A. N. Giannuzzo, M. E. Ludueña \& P. Araujo (Eds.), Santiago del Estero: una mirada ambiental. Santiago del Estero: Universidad Nacional de Santiago del Estero.

Toledo, V. M., Barrera Bassols, N. (2008). La memoria biocultural. La importancia ecológica de las sabidurías tradicionales. Barcelona: Icaria.

Villalba, A., Gómez Herrera, A., Concha Merlo, P. Y., \& Ferreyra, R. (2016). Procesos de producción de novedades socio-productivas en el manejo del monte y el ganado: experiencias de encierros comunitarios ganaderos en el Noreste de Santiago del Estero. In M. Gutiérrez \& V. González (Eds.), Desarrollo rural, política pública y agricultura familiar: reflexiones en torno a experiencias de la agricultura familiar en Santiago del Estero (pp. 69-88). San Miguel de Tucumán: Magna. 